\title{
Early SD-OCT diagnosis followed by prompt treatment of radiation maculopathy using intravitreal bevacizumab maintains functional
} visual acuity

\author{
This article was published in the following Dove Press journal: \\ Clinical Ophthalmology \\ 26 October 2012 \\ Number of times this article has been viewed
}

Purpose: To evaluate the benefits of intravitreal bevacizumab in patients with visually compromising radiation maculopathy following iodine-125 plaque brachytherapy for uveal melanoma.

Methods: In this Institutional Review Board-approved, consecutive, retrospective study from 2006-2009 of patients maintaining 20/50 or better vision following treatment for visually compromising radiation maculopathy, patients were evaluated with spectral domain optical coherence tomography at 2-4 month intervals following plaque removal. Treatment with intravitreal bevacizumab commenced at the first signs of radiation vasculopathy on spectral domain optical coherence tomography with associated decreased best corrected visual acuity, followed by repeat injections for recurrent or persistent vasculopathic changes.

Results: At 3 years following plaque brachytherapy, 81 of 159 (50.9\%) patients treated for radiation maculopathy demonstrated 20/50 or better vision at median follow up of 36 months, which demonstrates significant improvement in vision as compared to the Collaborative Ocular Melanoma Study $(P<0.0001)$. These 81 patients were given a mean of five injections (range $1-17$ ) over a mean of 17.6 months (range 1-54 months), starting at 15.8 months (range 3-50 months) after plaque brachytherapy. For those eyes that maintained 20/50 or better vision at the final follow-up, pretreatment mean best corrected visual acuity of 20/43 improved to 20/31.

Conclusion: This study demonstrates that spectral domain optical coherence tomography can detect early vasculopathic changes secondary to radiation maculopathy and that prompt treatment with intravitreal bevacizumab may delay vision loss and maintain or possibly improve visual acuity in half of eyes diagnosed with radiation maculopathy. Radiation maculopathy remains a therapeutically manageable morbidity associated with radiation therapy for posterior uveal melanoma.

Keywords: intravitreal bevacizumab, plaque brachytherapy, BCVA, radiation maculopathy, uveal melanoma

\section{Introduction}

Radiation treatments, which include external beam radiation, plaque brachytherapy, proton beam radiation, helium ion radiotherapy, and gamma knife radiotherapy, ${ }^{1-10}$ may result in long-term damage to the retinal vascular endothelial cells, causing radiation maculopathy in over $50 \%$ of eyes undergoing plaque radiotherapy. ${ }^{2,11}$ This process involves apoptosis, cell migration, clotting cascades, increased vascular endothelial permeability, aneurysm formation, telangiectasia, and neovascularization. ${ }^{12}$
Correspondence: Timothy G Murray Murray Ocular Oncology and Retina, 6705 Red Road Suite-412,

Miami, FL 33143, USA

$\mathrm{Tel}+\mathrm{I} 3054877470$

Fax +I 7865674380

Email tmurray@murraymd.com 
Other radiation effects on the eye include cataract formation, radiation optic neuropathy, retinal detachment, neovascular glaucoma, nerve-fiber layer infarcts, retinal hemorrhages, and vitreous hemorrhage. ${ }^{3,13-15}$

Radiation damage can be detected and classified through clinical examination, fluorescein angiography, or optical coherence tomography (OCT). ${ }^{16-18}$ OCT classification is gaining popularity in the detection and monitoring of radiationinduced macular edema, and can be graded on a 1-5 scale. ${ }^{13}$ This edema grading scale has also been shown to correlate with foveal thickness and visual acuity. ${ }^{13}$ Recent findings utilizing spectral domain OCT (SD-OCT) to detect intraretinal cystic spaces and photoreceptor loss have demonstrated that these earliest signs of radiation maculopathy manifest as macular edema, ${ }^{19}$ with average onset of OCT-evident edema by 12 months or up to 5 months earlier than clinically detectable radiation maculopathy and as early as 4 months after radiation treatment. ${ }^{20-23}$ The potential reversibility of damage from macular edema can serve as a critical time point for therapeutic intervention. ${ }^{21}$

Antivascular endothelial growth factor (anti-VEGF) agents have been proposed for the treatment of radiationrelated complications. Bevacizumab is a recombinant, humanized, monoclonal immunoglobulin G1, anti-VEGF antibody that has demonstrated significant clinical benefit in several solid tumors. ${ }^{24}$ The antibody binds to VEGF, a proangiogenic cytokine that plays a prominent role in the growth of tumor-specific vasculature in solid tumors. ${ }^{28}$ Studies on eyes harboring choroidal melanomas have demonstrated statistically significant increases in the levels of VEGF in both aqueous and vitreous samples compared to eyes without tumors. ${ }^{25}$ Of note, tumors previously treated with radiation therapy displayed the highest VEGF concentrations. These results have been confirmed and have been shown to correlate with larger basal diameter and tumor height. ${ }^{26,27}$ Recently, intravitreal bevacizumab has been effectively used in multiple retinal diseases, including age-related macular degeneration, retinal vein occlusions, diabetic macular edema, and neovascularization. ${ }^{28-33}$ In mice models, bevacizumab has shown no neuronal toxicity or retinal apoptosis, ${ }^{28}$ and clinical case series have suggested potential efficacy of these agents for radiation-induced maculopathy. ${ }^{34-38}$ The largest case series to date by Finger and Chin on 21 patients with iodine-125 brachytherapyinduced radiation maculopathy found that administration of $1.25 \mathrm{mg} / 0.05 \mathrm{~mL}$ bevacizumab lead to decreased macular edema, improved or maintained visual acuity, and reduced hemorrhage and retinal edema. ${ }^{39}$ Although anecdotal evidence in small case series has demonstrated the efficacy of anti-VEGF agents for radiation maculopathy, to date there have been no large case series or clinical trials evaluating this treatment. ${ }^{13,40}$

At Bascom Palmer Eye Institute, improvements in BCVA from bevacizumab usage have been observed in nearly half of the patients with radiation maculopathy, especially when commenced at the first signs of visual compromise. The Institute's efforts lie in maintaining visual acuity and globe salvage for patients suffering visually compromising radiation maculopathy. Hence, at Bascom Palmer Eye Institute, intravitreal bevacizumab is routinely administered in patients with OCT-evidence of radiation maculopathy and a best corrected visual acuity (BCVA) of 20/25 or worse. Therefore, the purpose of this study was to evaluate the 3 -year benefits on visual acuity of intravitreal bevacizumab for treatment of radiation maculopathy in patients that maintained vision of 20/50 or better.

\section{Methods}

\section{Patients}

The University of Miami Institutional Review Board approved this retrospective study. Inclusion criteria included patients that had maintained 20/50 or better vision after developing radiation maculopathy from iodine- 125 plaque brachytherapy for uveal melanoma from 2006-2009. Patients were followed up for a minimum of 6 months and were evaluated with SDOCT (Heidelberg Engineering GmbH, Heidelberg, Germany) at 2-4 month intervals following plaque removal. Treatment with intravitreal bevacizumab commenced at the first signs of radiation vasculopathy with BCVA of 20/25 or worse, followed by repeat injections for persistent vasculopathic changes and a vision of 20/25 or worse.

\section{Plaque brachytherapy procedure}

All patients presenting with posterior uveal melanoma underwent iodine-125 radioactive plaques using standard surgical techniques. ${ }^{41-43}$ A standard Collaborative Ocular Melanoma Study (COMS) plaque (a Silastic implant including integrated iodine-125 seed grooves placed into a gold-backed shield) with iodine-125 plaque seeds designed to deliver 85 Gy to the tumor apex was used in all cases. After the plaque was brought into the field, 5-0 nylon sutures were used to place the plaque, and the position was tested with intraoperative ultrasound by either the surgeon (TGM) or a registered diagnostic medical ultrasonographer using a contact B-scan instrument (Ophthascan ${ }^{\circledR}$ S; Alcon Surgical Inc, Irvine, CA or Innovative Imaging Inc, Sacramento, CA). Echographic studies were 
performed to acquire both longitudinal and transverse plaque views relative to the tumor. ${ }^{44-46}$ Photographic documentation and hard copy records were obtained. If removed, rectus muscles were reattached, and the conjunctiva was closed. The operative eye was patched and covered with a lead shield, and the plaque was removed after a mean of 3 days and 3 hours (range 3-4 days).

\section{Bevacizumab injections}

Patients were evaluated with SD-OCT at 2-4 month intervals following plaque removal, along with complete ophthalmic examination including indirect ophthalmoscopy, echography, and wide-field imaging. Treatment with $1.25 \mathrm{mg} / 0.05 \mathrm{cc}$ intravitreal bevacizumab commenced at the first signs of radiation vasculopathy as detected by $\mathrm{SD}-\mathrm{OCT}$ evidence of macular edema. ${ }^{13}$ The need for repeat injections for recurrent or persistent vasculopathic changes was associated with a lack of improvement or decline in BCVA. Cases refractory to bevacizumab alone were given intravitreal injection with $4 \mathrm{mg} / 0.1 \mathrm{cc}$ triamcinolone acetonide. Radiation maculopathy was graded in a blinded fashion using the following classification system: grade 1 indicates extrafoveal, noncystoid edema; grade 2, extrafoveal cystoid edema; grade 3, foveal noncystoid edema; grade 4, mild-to-moderate foveal cystoid edema; and grade 5, severe foveal cystoid edema. ${ }^{13}$ The authors also proposed a grade 6 to be added to the OCT classification, which indicates severe foveal cystoid edema with subretinal fluid. Patients were examined every 6 months by medical oncology.

\section{Analysis}

Eyes treated with intravitreal bevacizumab for radiation maculopathy that demonstrated BCVA of 20/50 or better were evaluated. Mean visual acuity was calculated using logarithm of the minimal angle of resolution analysis. Numerical values of 20/4000, 20/8000, 20/20,000, and 20/200,000 represented counting fingers, hand movement, light perception, and enucleation, respectively. The proportion of radiation retinopathy patients in the current series that maintained $20 / 50$ or better were compared to the proportion of all patients with plaque in the COMS series that maintained 20/50 or better using Fisher's two-tailed analysis.

\section{Results}

Of the subset (mean age 63 years) of patients showing improvement in visual acuity after 3 years, the mean maximal base was $13.1 \mathrm{~mm}$ (median $14 \mathrm{~mm}$; range 4.5 $18.5 \mathrm{~mm})-0.6 \mathrm{~mm}$ smaller than the mean of the entire series, and mean tumor height was $3.2 \mathrm{~mm}$ (median $2.9 \mathrm{~mm}$; range $1.1-17.1 \mathrm{~mm})-0.8 \mathrm{~mm}$ smaller than the mean of the entire series of radiation retinopathy patients (Table 1). Table 2 further characterizes the vision and treatment course for this subset.

Of 159 patients treated with intravitreal bevacizumab for radiation retinopathy from 2006-2009, 81 (50.9\%) were able to maintain a BCVA of 20/50 or better 3 years following plaque brachytherapy. Fifteen eyes demonstrated 20/20 vision (18.5\%), 18 eyes had 20/25 (22.2\%), 18 eyes had 20/30 (22.2\%), 26 eyes had 20/40 (32.1\%), and four eyes had 20/50 (5\%) vision. These 81 patients were given a mean of five injections (range 1-17) over a mean of 17.6 months (range 1-54 months), starting at 15.8 months after plaque brachytherapy. Mean BCVA prior to plaque placement was $20 / 34$. At the time of first detection of radiation maculopathy via SD-OCT and thus administration of first intravitreal antiVEGF injection, mean BCVA for this subset was 20/43, which improved to 20/31 34.6 months (median 36 months) after plaque brachytherapy (Figure 1, Table 3). Improvement from pretreatment to posttreatment visual acuity was statistically significant $(P<0.001$, paired $t$-test). While no large studies to the authors' knowledge serve as a comparative control investigating 3 years of visual acuity in eyes with radiation maculopathy, it is interesting to note that after 36 months follow-up in the COMS study, only $30.9 \%$ of radioactive plaque patients demonstrated 20/40 or better BCVA.

In the current series, 81 of 159 radiation maculopathy eyes (50.9\%) maintained 20/50 or better vision after 3 years. Sixteen of those 81 eyes (19.8\%) underwent treatment with additional laser photocoagulation or pars plana vitrectomy for radiation retinopathy compared to 53/159 eyes (33.3\%) in the entire series of radiation maculopathy patients. Noted complications included neovascular glaucoma requiring topical medication in $12.3 \%$ (four eyes) of the subset of patients able to maintain $20 / 50$ or better vision after 3 years

Table I Tumor characteristics

\begin{tabular}{ll}
\hline Tumor characteristics & $\begin{array}{l}\text { Number of patients } \\
(\mathbf{n}=\mathbf{8} \text { I) }\end{array}$ \\
\hline Size & 3 \\
Small & 32 \\
Medium & 62 \\
Large & 16 \\
Location & \\
$\quad$ Choroidal & $33(40.7 \%)$ \\
Juxtapapillary & $14(17.2 \%)$ \\
Ciliary body/choroid & $21(25.9 \%)$ \\
Macular involvement & $13(16 \%)$ \\
\hline
\end{tabular}


Table 2 Patient demographics and treatment information

\begin{tabular}{|c|c|c|c|}
\hline Outcomes & Values & COMS report number 16* & $P$ value \\
\hline Final BCVA of $20 / 50$ or better & $\mathrm{n}=81 / 159$ & & \\
\hline in radiation maculopathy patients & ( $50.9 \%$ of radiation maculopathy patients) & & \\
\hline Mean follow-up time after plaque & 34.6 months (range $9-70$ months) & 36 months & \\
\hline Median follow-up time & 36 months & & \\
\hline Mean time for radiation & 15.8 months & & \\
\hline maculopathy development & (range 3-50 months) & & \\
\hline Mean follow-up time after & 17.6 months & & \\
\hline radiation maculopathy & (range I-54 months) & & \\
\hline Male, female & $55 \%, 45 \%$ & & \\
\hline Mean age & 62.6 years & & \\
\hline Mean number of injections** & 5.0 (range I-I7) & & \\
\hline Preradiation BCVA & $20 / 34$ & & \\
\hline Pretreatment mean macular edema & 3.3 (range I-5) & & \\
\hline Posttreatment BCVA & $20 / 31$ & & \\
\hline Posttreatment mean foveal thickness & $3 \mid 2.8 \mu \mathrm{m}$ (median $295 \mu \mathrm{m}$; range $209-66 \mathrm{I} \mu \mathrm{m})$ & & \\
\hline Posttreatment mean macular edema & $1.9($ range I-5) & & \\
\hline Final BCVA $20 / 40$ or better & $\mathrm{n}=77 / 159$ & $\mathrm{n}=|55 / 50|$ & $P<0.000 I^{*,+}$ \\
\hline in radiation maculopathy patients & ( $48.4 \%$ of radiation maculopathy patients) & (30.9\% patients with plaque) & \\
\hline Mean BCVA after first injection & $20 / 43$ & & \\
\hline Mean BCVA at final visit & $20 / 31$ & & \\
\hline
\end{tabular}

and $7.5 \%$ (twelve eyes) in the entire series, as well as cataract development in $24.7 \%$ (20/81 eyes) of the subset and $36.5 \%$ (58/159 eyes) of the entire series, all of which were treated with phacoemulsification therapy. Seven patients with severe radiation retinopathy that were refractory to treatment with bevacizumab alone underwent treatment with additional triamcinolone therapy, of which one patient was able to maintain 20/50 or better vision at 3 years.

For the patients showing improvement in visual function following intravitreal injections of bevacizumab $(n=81)$, foveal thickness was stabilized with a decrease to $313 \mu \mathrm{m}$ (range 209-661 $\mu \mathrm{m}$ ) after a mean of five injections over the

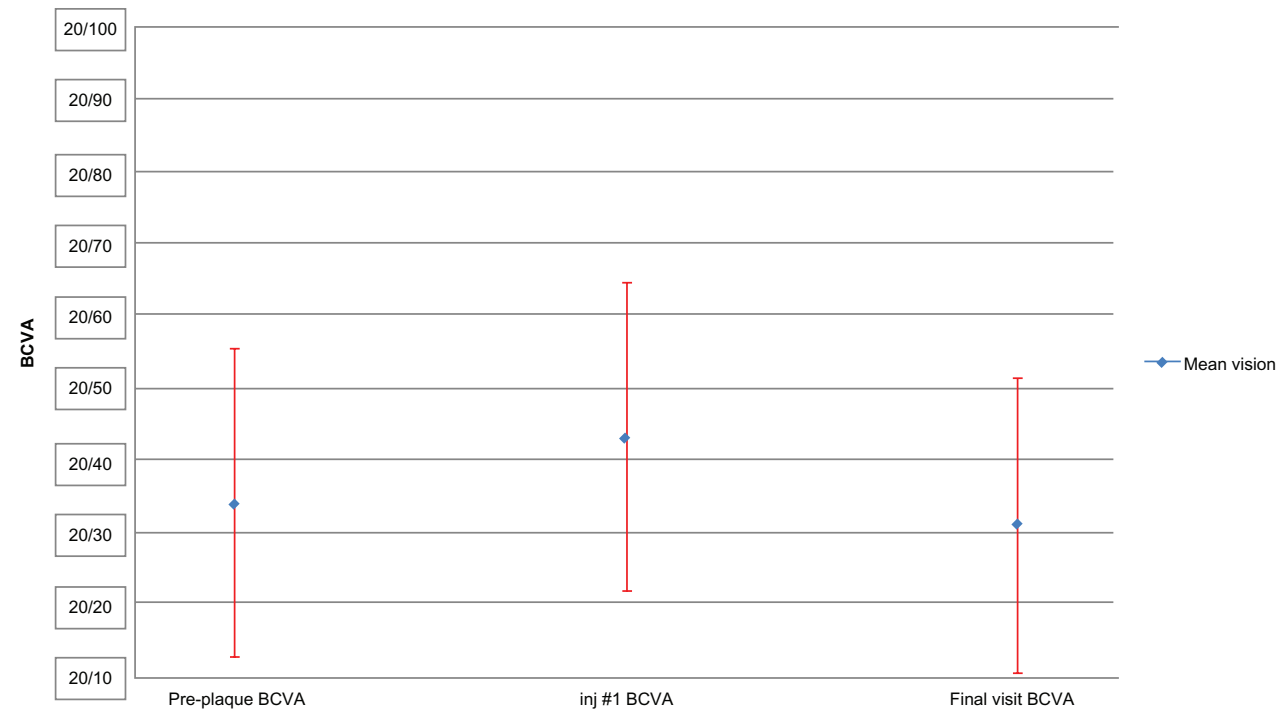

Figure I Mean best corrected visual acuity for the subset of patients maintaining 20/50 or better vision.

Notes: Eighty-one patients were given a mean of five injections (range I-I7) over a mean of 17.6 months (range I-54 months), starting at I5.8 months after plaque brachytherapy. For this subset, the preplaque mean (logarithm of the minimal angle of resolution) best corrected visual acuity of $20 / 34$ deteriorated to $20 / 43$ at first presentation of radiation maculopathy, and eventually improved to mean best corrected visual acuity of $20 / 3 \mathrm{I}$ at their final visit $(P<0.00 \mathrm{I}$, paired $t$-test).

Abbreviations: BCVA, best corrected visual acuity; inj \#I, first injection; plq, plaque. 
Table 3 Percentage of best corrected visual acuity for available patients in each visual category for the 3-year follow-up period following plaque brachytherapy

\begin{tabular}{lllllllll}
\hline $\begin{array}{l}\text { Best corrected } \\
\text { visual acuity }\end{array}$ & $\begin{array}{l}\text { Preplaque } \\
\text { brachytherapy }\end{array}$ & $\begin{array}{l}\mathbf{2 - 4} \\
\text { months }\end{array}$ & $\begin{array}{l}\mathbf{5 - 7} \\
\text { months }\end{array}$ & $\begin{array}{l}\mathbf{8 - I 4} \\
\text { months }\end{array}$ & $\begin{array}{l}\mathbf{I 5 - 2 0} \\
\text { months }\end{array}$ & $\begin{array}{l}\mathbf{2 I - 2 7} \\
\text { months }\end{array}$ & $\begin{array}{l}\mathbf{2 8 - 3 3} \\
\text { months }\end{array}$ & $\begin{array}{l}\mathbf{3 4 +} \\
\text { months }\end{array}$ \\
\hline $20 / 20$ or better & $25.9 \%$ & $25.9 \%$ & $25.9 \%$ & $28.9 \%$ & $31.2 \%$ & $40.3 \%$ & $26.5 \%$ & $23.1 \%$ \\
$20 / 25-20 / 50$ & $58.0 \%$ & $58.1 \%$ & $56.8 \%$ & $59.2 \%$ & $59.7 \%$ & $58.2 \%$ & $67.4 \%$ & $76.9 \%$ \\
$20 / 60-20 / 80$ & $8.7 \%$ & $12.3 \%$ & $12.3 \%$ & $6.6 \%$ & $3.9 \%$ & $1.5 \%$ & $6.1 \%$ & $0 \%$ \\
$20 / 100-20 / 160$ & $3.7 \%$ & $2.5 \%$ & $3.7 \%$ & $3.9 \%$ & $2.6 \%$ & $0.0 \%$ & $0.0 \%$ & $0 \%$ \\
$20 / 200-20 / 320$ & $2.5 \%$ & $1.2 \%$ & $1.2 \%$ & $0.0 \%$ & $1.3 \%$ & $0.0 \%$ & $0.0 \%$ & $0 \%$ \\
$20 / 400-20 / 640$ & $1.2 \%$ & $0.0 \%$ & $0.0 \%$ & $0.0 \%$ & $0.0 \%$ & $0.0 \%$ & $0.0 \%$ & $0 \%$ \\
$20 / 800$ or worse & $0.0 \%$ & $0.0 \%$ & $0.0 \%$ & $1.3 \%$ & $1.3 \%$ & $0.0 \%$ & $0.0 \%$ & $0 \%$ \\
Total patients & 81 & 81 & 81 & 76 & 77 & 67 & 49 & 39 \\
Mean visual acuity & $20 / 35$ & $20 / 34$ & $20 / 34$ & $20 / 33$ & $20 / 33$ & $20 / 29$ & $20 / 31$ & $20 / 30$ \\
\hline
\end{tabular}

Notes: Patients include those that developed radiation maculopathy and maintained $20 / 50$ or better vision at their final follow-up visit $(n=8 I)$.

course of 17.6 months (Figure 2). For these patients, at the time of radiation maculopathy diagnosis, mean radiation maculopathy grade of 3.3 declined to a mean grade of 1.9 at the final follow-up visit, an improvement which was statistically significant $(P<0.0001)$.

\section{Discussion}

Exploring potential therapies for radiation-related complications remains a crucial subject in ocular oncology. Reports show that half of all patients treated with iodine- 125 plaque brachytherapy lose at least six Snellen lines of vision
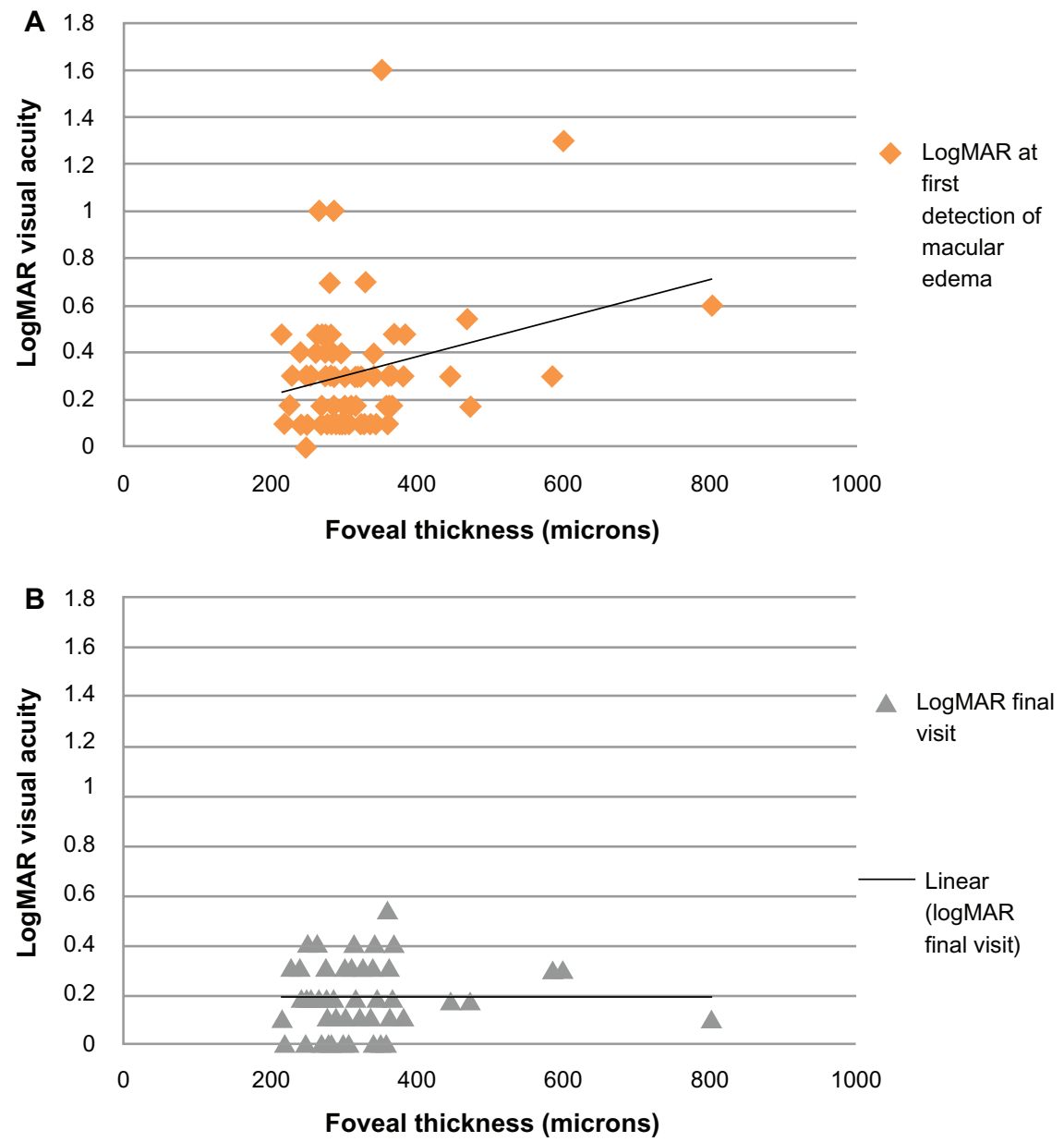

Figure 2 Correlation between foveal thickness and logarithm of the minimal angle of resolution $(\mathbf{A})$ at first detection of macular edema and (B) after antivascular endothelial growth factor treatments.

Abbreviation: logMAR, logarithm of the minimal angle of resolution. 
within 3 years, with $43 \%$ having visual acuity worse than $20 / 200$ and only $34 \%$ of patients demonstrating $20 / 40$ or better vision at the final follow-up. ${ }^{2,13}$ Thus, the need to investigate more effective treatment modalities to preserve and maintain functional vision in patients developing radiation maculopathy is warranted. ${ }^{2,38,47}$ Although various treatment modalities for radiation maculopathy have been investigated, including hyperbaric oxygen, ${ }^{48}$ laser photocoagulation, ${ }^{49}$ and triamcinolone acetate, ${ }^{13}$ there has been limited success regarding the effective treatment of radiation-induced macular edema. ${ }^{13}$

In a study by Finger and Kurli, two groups of patients were treated with laser photocoagulation (one with evidence of radiation maculopathy and one "high-risk" group). In patients with radiation maculopathy, sector laser photocoagulation led to a regression of maculopathy in approximately $65 \%$ of patients and only $15 \%$ lost three or more lines of vision. Interestingly, only $19 \%$ of patients treated with prophylactic laser prior to clinically evident disease later developed maculopathy. No patient in the prophylactic laser group lost three or more lines. ${ }^{49}$ Another study by Kinyoun showed improved mean final visual acuity by 0.34 logarithm of the minimal angle of resolution LogMAR after 51 months in 19 patients undergoing grid laser treatment compared to 23 untreated controls. ${ }^{50} \mathrm{~A}$ single report by Bakri and Beer has suggested the beneficial role of verteporfin photodynamic therapy following focal laser for radiation edema, although the potential mechanism of effect is unknown. ${ }^{51}$ Periocular triamcinolone has also been investigated for radiation maculopathy, showing sustained benefit 6 months after treatment. ${ }^{52}$

Triamcinolone administered at the time of plaque removal and at 4-month intervals has demonstrated a decrease in rates of macular edema, as well as moderate to severe vision loss. ${ }^{13}$ Using intravitreal triamcinolone, Shields et al reported a decline in mean foveal thickness from $417 \mu \mathrm{m}$ to $207 \mu \mathrm{m}$ a month following treatment, and a stable or improved visual acuity in $45 \%$ of 31 patients by 6 months. ${ }^{53}$ In the authors' experience, triamcinolone is often utilized as a consolidation therapy. For patients with massive macular edema and cystic changes where bevacizumab does not lead to significant improvement, combination treatment with bevacizumab followed by supplemental triamcinolone may often stabilize the macular edema. However, these patients often have an altered inner segment/outer segment junction from the chronic macular edema, and despite improvement in the intraretinal fluid and restoration of retinal architecture, visual acuity rarely improves significantly.
A limited case series suggested that injections with bevacizumab could stabilize or improve visual acuity in up to $86 \%$ of patients, ${ }^{34}$ and further studies have demonstrated improvement in BCVA as early as 1 month after a single administration of bevacizumab. ${ }^{54}$ In the current study, all patients with visually compromising radiation maculopathy were treated with intravitreal bevacizumab at first signs of vasculopathic changes detected by SD-OCT.

Baseline median visual acuity in the COMS study was $20 / 32$, with a substantial decrease in vision at 3 years following plaque treatment to a median of 20/125. Of note, the COMS series included all 623 patients who received plaque brachytherapy, including those that may not have developed radiation maculopathy. Out of these patients, 49\% lost six or more lines of vision after 3 years. ${ }^{2}$ In the current study, the improvement in visual acuity was significantly better $(P<0.0001)$. It was found that $48.4 \%$ of patients with visual compromising radiation maculopathy treated with intravitreal bevacizumab injections maintained $20 / 40$ or better vision at 3 year follow up; in contrast, the COMS study showed that only $30.9 \%$ of eyes maintained $20 / 40$ or better vision. ${ }^{2}$ In addition, a study by Char et al further showed that only $26 \%$ of total eyes receiving plaque therapy were able to retain $20 / 40$ or better vision at $2-3$ years following plaque brachytherapy. ${ }^{55}$

Fluorescein angiography utilized within COMS was not found to be correlated with early radiation maculopathy as detected by SD-OCT in the current study. Therefore, fluorescein angiography findings may represent later changes in macular anatomy, and this method was not found to be informative in evaluating patients with early BCVA decline associated with SD-OCT findings of radiation maculopathy. The current study emphasizes the importance of early identification using SD-OCT, and has demonstrated that early treatment with anti-VEGF agents may stabilize the retinal vasculature, decreasing vascular permeability, and resulting in a reconstitution of the blood-retinal barrier. In addition, anti-VEGF treatment may allow for a reduction of the mean macular edema grade that may occur as early as 4-6 weeks following intravitreal bevacizumab injection. ${ }^{36,54}$

In patients that maintained 20/50 or better BCVA by the final follow-up, evidence of macular edema onset by SD-OCT was found as early as 3 months following plaque radiotherapy, with a mean incidence of 15.8 months following plaque brachytherapy. Figure 3 shows SD-OCT images of patients that demonstrated a significant reduction in macular edema, with an improvement in visual acuity. In the current study, a positive correlation was also observed between initial 
A

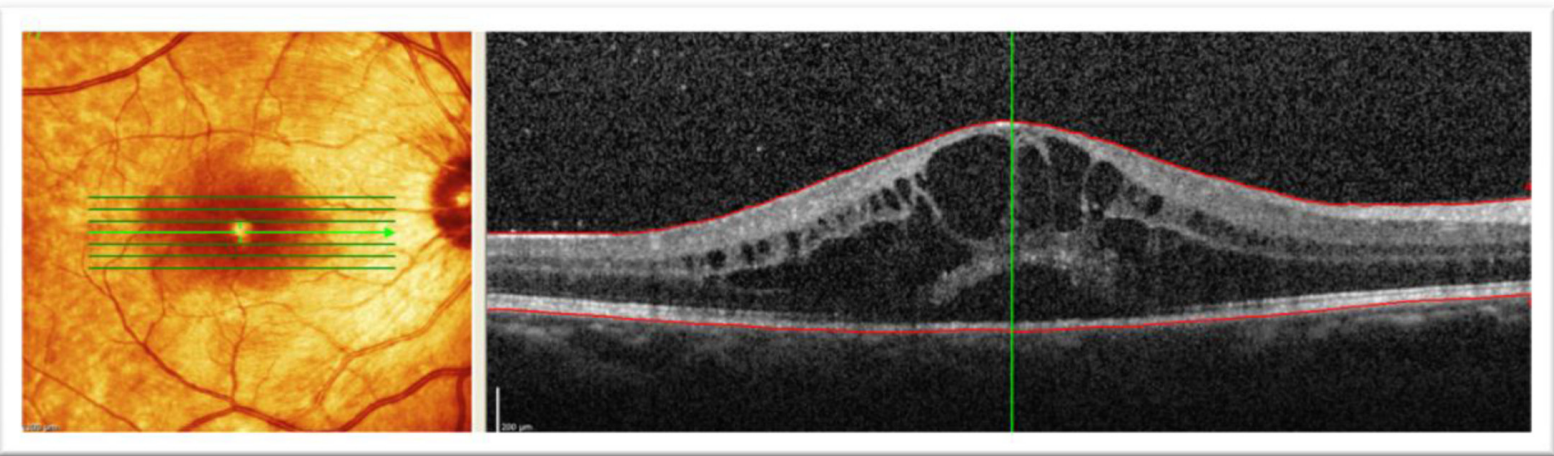

B

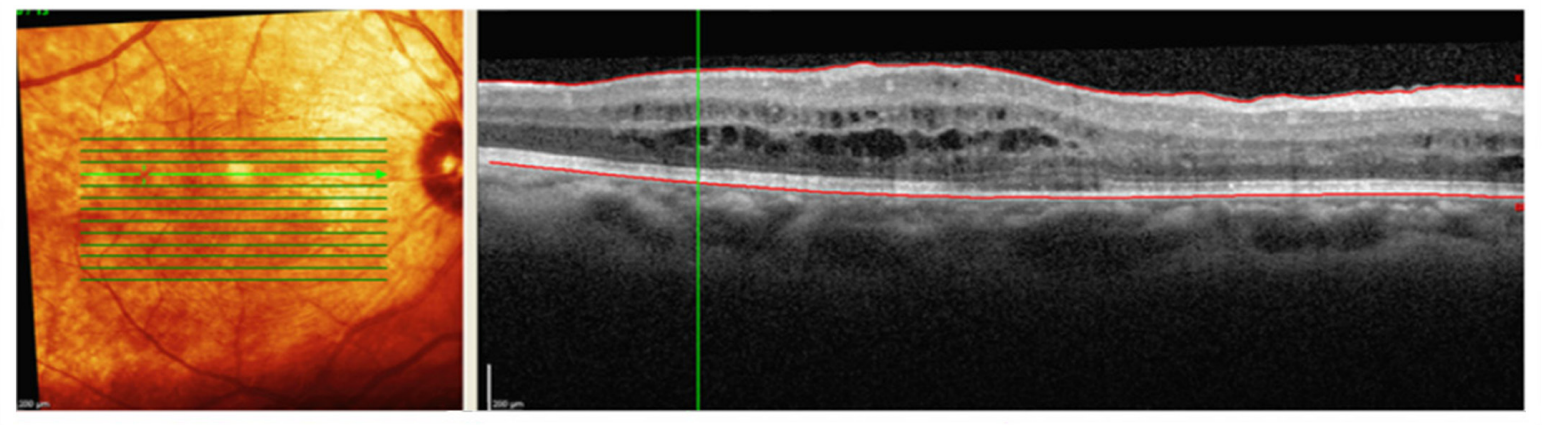

C

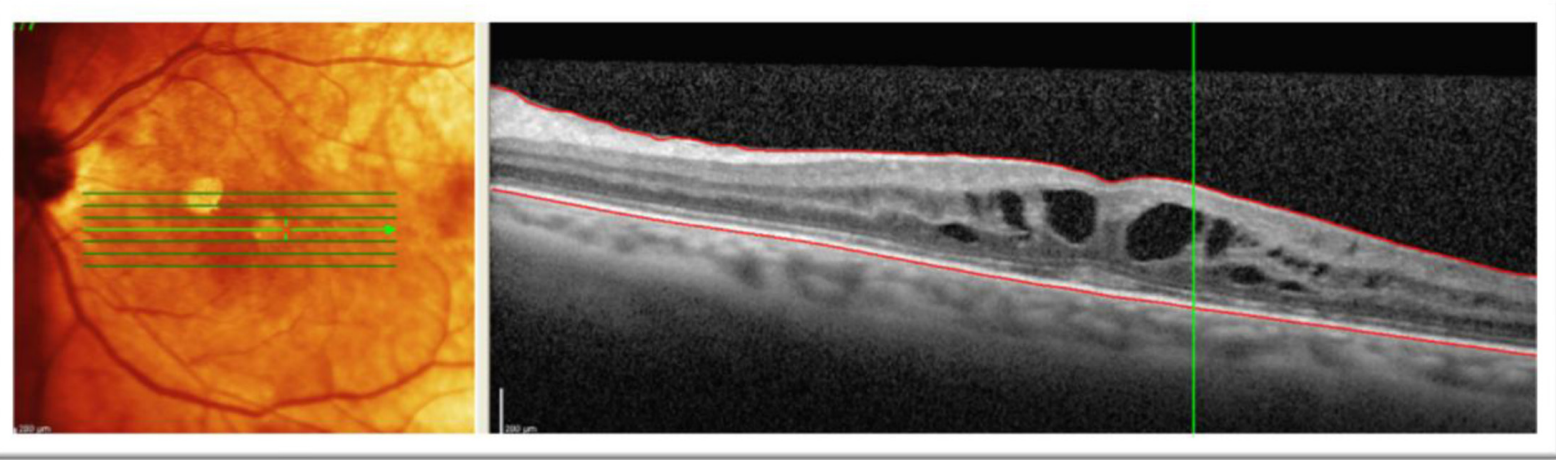

D
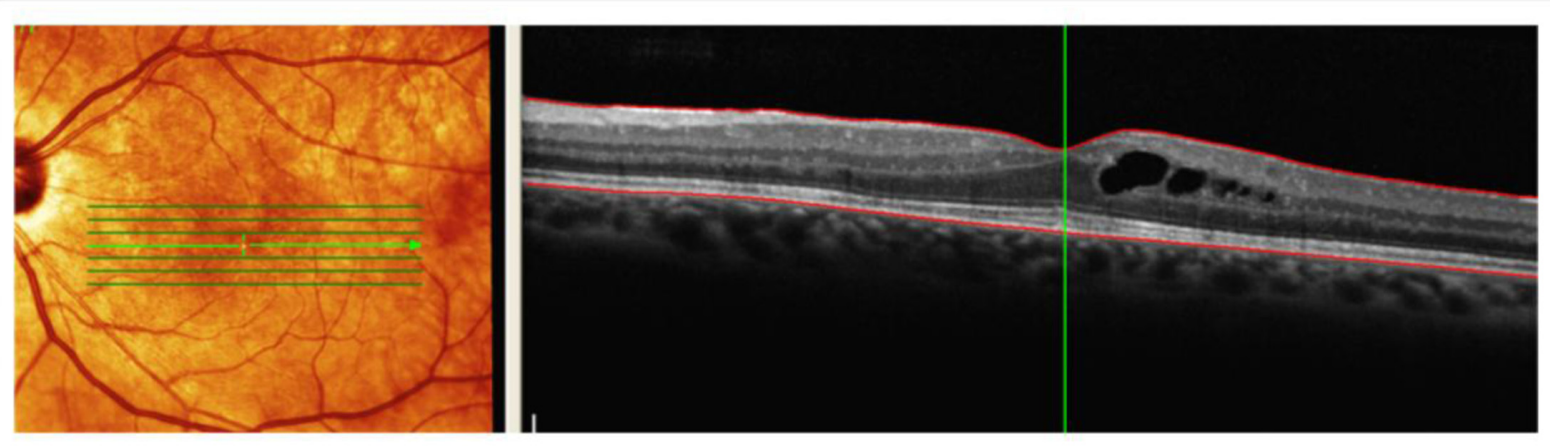

Figure 3 (Continued) 
E

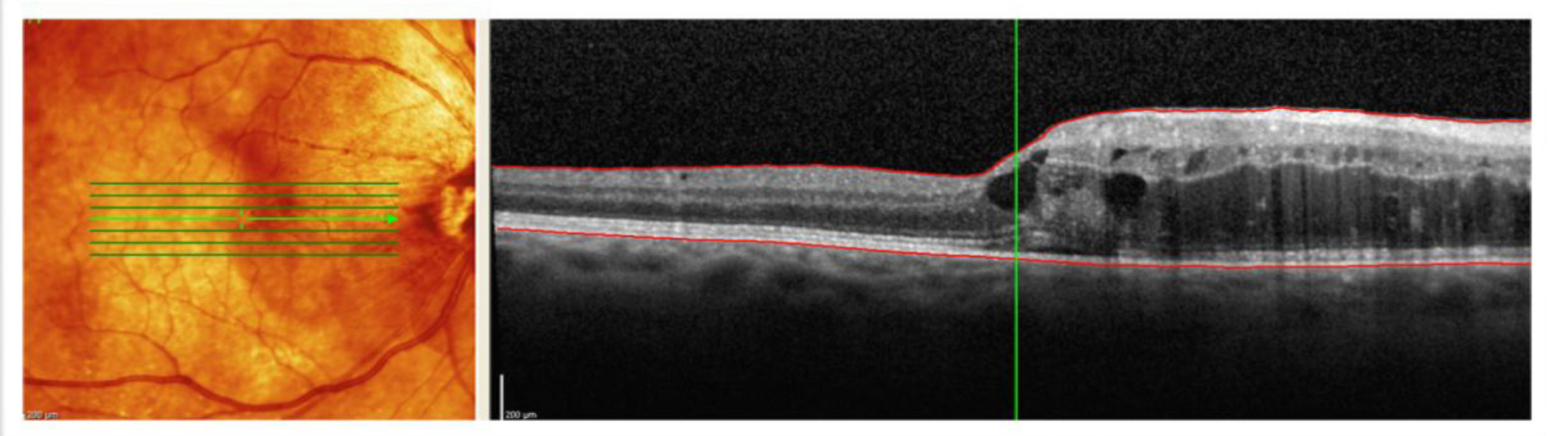

$\mathbf{F}$
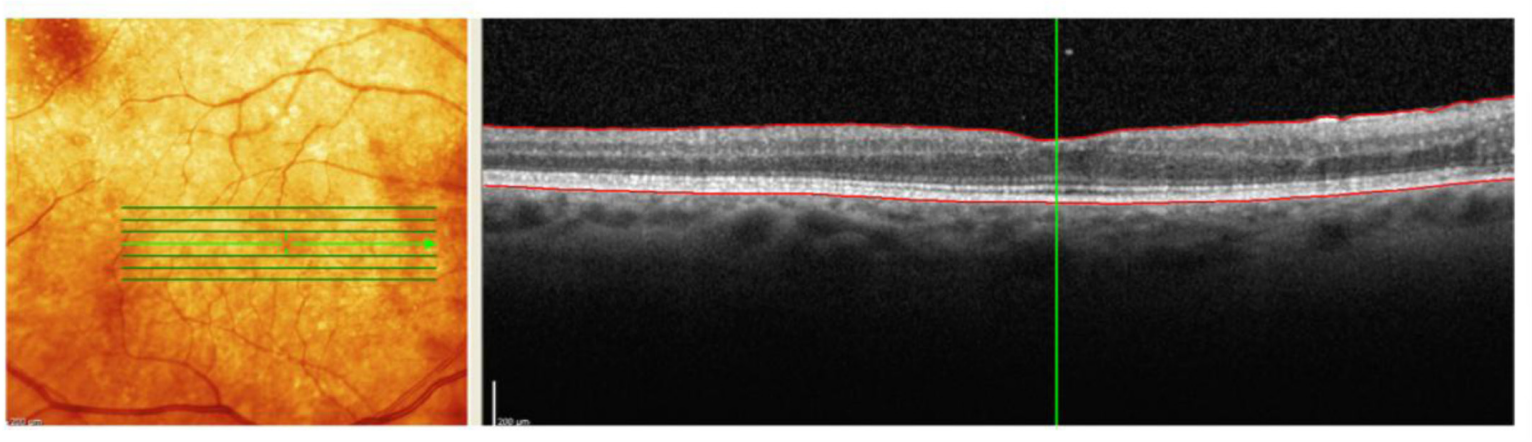

Figure 3 Spectral domain optical coherence tomographic images of three patients showing improvement in best corrected visual acuity to $20 / 50$ or better following bevacizumab treatments for radiation maculopathy. (A) Patient I: underwent plaque brachytherapy (right eye) with 20/25 vision at the time. Four years after treatment, the patient presented with subretinal fluid and foveal cysts, grade 6 with best corrected visual acuity of 20/80, and mean foveal thickness of $802 \mu$ m. (B) Patient I: after treatment with six intravitreal bevacizumab treatments over 19 months, visual acuity improved to $20 / 25$ and macular edema improved to grade 4 . Mean foveal thickness decreased to $339 \mu \mathrm{m}$. (C) Patient 2: underwent plaque brachytherapy (left eye) with 20/400 vision at the time. Twenty-two months after treatment with plaque brachytherapy, the patient presented with grade 5 macular edema and best corrected visual acuity of 20/70 with mean foveal thickness of $483 \mu \mathrm{m}$. (D) Patient 2: after treatment with five intravitreal antivascular endothelial growth factor injections over 12 months, visual acuity improved to 20/25, macular edema improved to grade 4 , and mean foveal thickness decreased to $366 \mu \mathrm{m}$. (E) Patient 3: presented with radiation maculopathy (grade 6) 3I months after treatment with plaque brachytherapy with 20/30 in the right eye and mean foveal thickness of $472 \mu \mathrm{m}$. (F) Patient 3: after receiving two intravitreal antivascular endothelial growth factor injections over 10 months, vision improved to $20 / 30$, macular edema grade resolved to normal from grade 6 , and mean foveal thickness decreased to $284 \mu \mathrm{m}$.

macular edema grade and final BCVA. ${ }^{13}$ It was also noted that some patients showing persistent macular edema at the final follow-up visit were still able to maintain functional visual acuity.

The current study suggests that despite visually significant radiation maculopathy, early treatment with intravitreal bevacizumab and repeated injections may maintain vision for a minimum of 35 months following plaque brachytherapy. Of note, the patients that maintained functional vision (20/50 or better) had good preinjection visual acuity (20/43), emphasizing the importance of early identification of macular edema with SD-OCT and early treatment prior to substantial vision loss.

Limitations to the current study include a relatively small sample size (although it is the largest to date), limited follow-up time of 3 years following plaque brachytherapy, its retrospective nature, and the inclusion of only a single institution. Furthermore, this study lacked a control group of patients with radiation retinopathy that did not receive any bevacizumab treatment. However, the goal of this study was to focus primarily on the 81 patients that were able to maintain functional visual acuity after treatment with bevacizumab. Radiation doses to the fovea were not calculated; however, similar rates of macular involvement (16\% versus $14.5 \%)$ when comparing the subset of patients that maintained 20/50 or better vision to the entire series of radiation maculopathy patients were noted. Radiation maculopathy complications were found to commence earlier than 3 years which may introduce some lead time bias. Additional studies are needed to investigate whether the effects of repeated intravitreal bevacizumab continues to be efficacious at future time points.

\section{Conclusion}

This study has demonstrated the importance of early identification of radiation maculopathy using SD-OCT. 
While radiation retinopathy can be visually devastating, early treatment of visually-compromising radiation maculopathy with targeted intravitreal bevacizumab shows promise in stabilizing and even improving vision, allowing many patients to maintain $20 / 50$ or better vision.

\section{Acknowledgment}

This study is supported in part, by the Melanoma Research Foundation.

\section{Disclosure}

The authors report no conflicts of interest in this work.

\section{References}

1. Hawkins BS. Collaborative Ocular Melanoma Study randomized trial of I-125 brachytherapy. Clin Trials. 2011;8(5):661-673.

2. Melia BM, Abramson DH, Albert DM, et al. Collaborative ocular melanoma study (COMS) randomized trial of 1-125 brachytherapy for medium choroidal melanoma. I. Visual acuity after 3 years COMS report No. 16. Ophthalmology. 2001;108:348-366.

3. Giuliari G, Sadaka A, Hinkle D, et al. Current treatments for radiation retinopathy. Acta Oncologica. 2011;50:6-13.

4. Jampol LM, Moy CS, Murray TG, Reynolds SM, et al. Collaborative Ocular Melanoma Study Group (COMS Group). The COMS randomized trial of iodine 125 brachytherapy for choroidal melanoma: IV. COMS report no. 19. Ophthalmology. Dec 2002;109(12): 2197-2206.

5. Finger PT, Chin KJ, Duvall G, Palladium-103 for Choroidal Melanoma Study Group. Palladium-103 ophthalmic plaque radiation therapy for choroidal melanoma: 400 treated patients. Ophthalmology. 2009;116:790-796.

6. Krema H, Somani S, Sahgal A, Xu W, Heydarian M, Payne D. Stereotactic radiotherapy for treatment of juxtapapillary choroidal melanoma: 3-year follow-up. Br J Ophthalmol. 2009;93:1172-1176.

7. Gragoudas ES, Seddon JM, Egan K, Glynn R, Munzenrider J, AustinSeymour M. Long-term results of proton beam irradiated uveal melanomas. Ophthalmology. 1987;94:349-353.

8. Haas A, Pinter O, Papaefthymiou G, Weger M, Berghold A, Schrottner O. Incidence of radiation retinopathy after high-dosage single-fraction gamma knife radiosurgery for choroidal melanoma. Ophthalmology. 2002;109:909-913.

9. Levy RP, Fabrikant JI, Frankel KA, Phillips MH, Lyman JT, Lawrence $\mathrm{JH}$. Heavy-charged-particle radiosurgery of the pituitary gland: Clinical results of 840 patients. Stereotact Funct Neurosurg. 1991;57:22-35.

10. Houston SK 3rd, Markoe AM, Boldt HC, Murray TG. Juxtapapillary uveal melanomas: patient outcomes after treatment with proton irradiation for peripapillary and parapapillary melanomas. Arch Ophthalmol. Sep 2011;129(9):1218-1220.

11. Diener-West M, Earle JD, Fine SL, et al. The COMS randomized trial of iodine 125 brachytherapy for choroidal melanoma, III: initial mortality findings. COMS Report No. 18. Arch Ophthalmol. 2001;119: 969-982.

12. Archer DB, Amoaku WM, Gardiner TA. Radiation retinopathy clinical, histopathological, ultrastructural and experimental correlations. Eye (Lond). 1991;51, 5(Pt 2):239-251.

13. Horgan N, Shields CL, Mashayekhi A, Teixeira LF, Materin MA, Shields JA. Early macular morphological changes following plaque radiotherapy for uveal melanoma. Retina. 2008;28:263-273.

14. Brown GC, Shields JA, Sanborn G, Augsburger JJ, Savino PJ, Schatz NJ. Radiation retinopathy. Ophthalmology. 1982;89:1494-1501.

15. Bosworth JL, Packer S, Rotman M, Ho T, Finger PT. Choroidal melanoma: I-125 plaque therapy. Radiology. 1988;169:249-251.
16. Massin P, Erginay A, Haouchine B, et al. Retinal thickness in healthy and diabetic subjects measured using optical coherence tomography mapping software. Eur J Ophthal. 2002;12:102-108.

17. Catier A, Tadayoni R, Paques M, et al. Characterization of macular edema from various etiologies by optical coherence tomography. Am J Ophthal. 2005;140:200-206.

18. Toth CA, Narayan DG, Boppart SA, et al. A comparison of retinal morphology viewed by optical coherence tomography and by light microscopy. Arch Ophthal. 1997 Nov;115 (11):1425-8.

19. Levitz LM. The use of optical coherence tomography to determine the severity of radiation retinopathy. Ophthalmic Surg Laswers Imaging. 2005;36:410-411.

20. Coker JG. Duker JS. Macular disease and optical coherence tomography. Curr Opin Ophthal. 1996;7:33-38.

21. Mukai SGD, Gragoudal ES. Radiation retinopathy. In: Albert DM JF, ed. Principles and practice of ophthalmology. Vol 2. Philadelphia: WB Saunders. 1994:1038-1041.

22. Guyer DR, Mukai S, Egan KM, Seddon JM, et al. Radiation maculopathy after proton beam irradiation for choroidal melanoma. Ophthalmology. 1992;99:1278-1285.

23. Horgan N, Shields C, Mashayekhi, et al. Classification and treatment of radiation maculopathy. Current Opinion in Ophthalmology. 2010; 21:233-238.

24. Folkman J.What is the evidence that tumors are angiogenesis dependent? J Natl Cancer Inst. Jan 3 1990;82(1):4-6.

25. Boyd SR, Tan D, Bunce C, Gittos A, et al. Vascular endothelial growth factor is elevated in ocular fluids of eyes harbouring uveal melanoma: identification of a potential therapeutic window. Br J Ophthalmol. Apr 2002;86(4):448-452.

26. Missotten GS, Notting IC, Schlingemann RO, et al. Vascular endothelial growth factor a in eyes with uveal melanoma. Arch Ophthalmol. Oct 2006;124(10):1428-1434.

27. Piña Y, Cebulla CM, Murray TG, et al. Blood vessel maturation in human uveal melanoma: spatial distribution of neovessels and mature vasculature. Ophthalmic Res. 2009;41(3):160-169.

28. Kim JH, Kim C, Kim JH, et al. Absence of intravitreal bevacizumabinduced neuronal toxicity in the retina. Neurotoxicology. Nov 2008; 29(6):1131-1135.

29. Ijland SA, Jager MJ, Heijdra BM, Westphal JR, Peek R. Expression of angiogenic and immunosuppressive factors by uveal melanoma cell lines. Melanoma Res. 1999;9:445-450.

30. Rosenfeld PJ, Schwartz SD, Blumenkranz MS, et al. Maximum tolerated dose of a humanized anti-vascular endothelial growth factor antibody fragment for treating neovascular age-related macular degeneration. Ophthalmology. 2005;112;1048-1105.

31. Campochiaro PA, Heier JS, Feiner L, et al. Ranibizumab for macular edema following branch retinal vein occlusion: six-month primary end point results of a phase III study. Ophthalmology. Jun 2010; 117(6):1102-1112.

32. Diabetic Retinopathy Clinical Research Network, et al. Rationale for the diabetic retinopathy clinical research network treatment protocol for center-involved diabetic macular edema. Ophthalmology. Dec 2011;118(12):5-14

33. Michaelides M, Fraser-Bell S, Hamilton R, et al. (Bolt Study): Report 1. Retina. May 2010;30(5):781-786.

34. Finger PT, Chin K. Anti-vascular endothelial growth factor bevacizumab (bevacizumab) for radiation retinopathy. Arch Ophthalmol. Jun 2007;125(6):751-756.

35. Stack R, Elder M, Abdelaal A, Hidajat R, Clemett R. New Zealand experience of I125 brachytherapy for choroidal melanoma. Clin Experiment Ophthalmol. 2005;33:490-494.

36. Mason JO3rd,Albert MA Jr, PersaudTO, Vail RS. Intravitreal bevacizumab treatment for radiation macular edema after plaque radiotherapy for choroidal melanoma. Retina. Sep 2007;27(7):903-907.

37. Gupta A, Muecke JS. Treatment of radiation maculopathy with intravitreal injection of bevacizumab (Avastin). Retina. Jul-Aug 2008;28(7):964-968. 
38. Finger PT, Mukkamala SK. Intravitreal anti-VEGF bevacizumab (Avastin) for external beam related radiation retinopathy. Eur J Ophthalmol. Jul 2011;21(4):446-451.

39. Finger PT. Radiation retinopathy is treatable with anti-vascular endothelial growth factor bevacizumab (Avastin). Int J Radiat Oncol Biol Phys. Mar 15 2008;70(4):974-977.

40. De Potter P, Shields CL, Shields JA, Cater JR, Brady LW. Plaque radiotherapy for juxtapapillary choroidal melanoma. Visual acuity and survival outcome. Arch Ophthalmol. 1996;114:1357-1365.

41. Char DH. Clinical ocular oncology, Churchill Livingstone, New York. 1989:117-121.

42. Shields JA, CL Shields Intraocular tumors, WB Saunders, Philadelphia. 1992:25-43.

43. Hui JI, Murray TG. Radioactive plaque therapy. Int Ophthalmol Clin. 2006;46(1):51-68.

44. Shah NV, Houston SK, Murray TG, Markoe AM. Evaluation of the surgical learning curve for I-125 episcleral plaque placement for the treatment of posterior uveal melanoma: a two decade review. Clinical Ophthalmology. 2012:6(447-452).

45. Harbour JW, Murray TG, Byrne SF, et al AM. Intraoperative echographic localization of iodine 125 episcleral radioactive plaques for posterior uveal melanoma. Retina. 1996;16(2):129-134.

46. Tabandeh H, Chaudhry NA, Murray TG, et al. Intraoperative echographic localization of iodine-125 episcleral plaque for brachytherapy of choroidal melanoma. Am J Ophthalmol. Feb 2000;129(2):199-204.
47. Newman H, Chin KJ, Finger PT. Subfoveal Choroidal Melanoma Pretreatment Characteristics and Response to Plaque Radiation Therapy. Arch Ophthalmol. 2011;129(7):892-898.

48. Levy RL, Miller NR. Hyperbaric oxygen therapy for radiation-induced optic neuropathy. Ann Acad Med Singapore. Mar 2006;35(3):151-157.

49. Finger PT, Kurli M. Laser photocoagulation for radiation retinopathy after ophthalmic plaque radiation therapy. Br J Ophthalmol. 2005; 89:730-738.

50. Kinyoun JL. Long term visual acuity results of treated and untreated radiation retinopathy (an AOS thesis). Trans Am Ophthal Soc. 2008;106:325-335.

51. Bakri SJ, Beer PM. Photodynamic therapy for maculopathy due to radiation retinopathy. Eye (Lond). 2005;19:795-799.

52. Sutter FK, Gillies MC. Intravitreal triamcinolone for radiation macular edema. Arch Ophthalmol. 2003;121:1491-1493.

53. Shields CL, Demirci H. Dai V, et al. Intravitreal triamcinolone acetonide for radiation maculopathy after plaque radiotherapy for choroidal melanoma. Retina. 2005;25:868-874.

54. Ziemssen F, Voelker M, Alpeter E, et al. Intravitreal bevacizumab treatment of radiation maculopathy due to brachytherapy in choroidal melanoma. Acta Ophthalmol Scand. 2007;85:579-580.

55. Char DH, Quivey JM, Castro JR, et al. Helium ions versus iodine 125 brachytherapy in the management of uveal melanoma. Ophthalmology. 1993;100:1547-1554.
Clinical Ophthalmology

\section{Publish your work in this journal}

Clinical Ophthalmology is an international, peer-reviewed journal covering all subspecialties within ophthalmology. Key topics include: Optometry; Visual science; Pharmacology and drug therapy in eye diseases; Basic Sciences; Primary and Secondary eye care; Patient Safety and Quality of Care Improvements. This journal is indexed on Submit your manuscript here: http://www.dovepress.com/clinical-ophthalmology-journal

\section{Dovepress}

PubMed Central and CAS, and is the official journal of The Society of Clinical Ophthalmology (SCO). The manuscript management system is completely online and includes a very quick and fair peer-review system, which is all easy to use. Visit http://www.dovepress.com/ testimonials.php to read real quotes from published authors. 